\title{
REESTRUTURAÇÃO DA DISCIPLINA ENFERMAGEM PEDIÁTRICA DO CURSO DE GRADUAÇÃO DA ESCOLA DE ENFERMAGEM DA UNIVERSIDADE FEDERAL DE MINAS GERAIS: AVALIAÇÃO DO PROCESSO
}

\author{
Iêda Maria Andrade Paulo* \\ Janet Fontes* \\ Lélia Maria Madeira* \\ Lindalva Carvalho Armond* \\ Maristela Colombini Duarte Garcia*
}

PAULO. I.M.A. et al. Reestruturaçáo da disciplina Enfermagem Pediátrica do Curso de

Graduaçăo da Escola de Enfermagem da Universidade Federal de Minas Gerais: avaliaçå

do processo. Rev.Esc.Enf.USP, v.29, n.2, p.115-32, ago. 1995.

Neste trabalho os professores da disciplina Enfermagem Pediátrica do Curso de Graduação de Enfermagem da UFMG fazem avaliaçāo de um projeto de ensino que propõe a reestruturação da disciplina, tendo como base a abordagem do processo ensino-aprendizagem apresentada por ABBATT; MACMHON (1985). As autoras avaliam os resultados decorrentes das mudanças propostas, do ponto de vista dos professores e dos alunos. Ambos destacam os pontos positivos da reestruturação e a importância da continuidade da mesma.

UNITERMOS:Educação em Enfermagem. Enfermagem Pediátrica. Ensino em Enfermagem Pediátrica.

\section{HISTÓRICO}

$\Lambda$ disciplina Enfermagem Pediatrica compõe o currículo mínimo do Curso de Graduação em Enfermagem e Obstétrica da Universidade Federal de Minas Gerais.

* Professores da Disciplina Enfermagem Pediátrica do Curso de Graduação da Escola de Enfermagem da Universidade Federal de Minas Gerais. 
Essa disciplina of oferecida semestralmente a alunos do $7^{\circ}$ período, desenvolvendo-se atraves de um conteúdo tébrico e prático, ministrado por 8 docentes, num total de 210 horas, sendo 60 horas para a teoria e 150 horas para a prática.

O programa da disciplina engloba cinco unidades básicas: situação de saúde da criança e do adolescente; educação participativa em saúde; programas de assistência integral à saúde da criança e principais riscos que acometem a criança institucionalizada.

Em 1986, os professores da disciplina Enfermagem Pediátrica, considerando as dificuldades no desenvolvimento das atividades práticas, propuseram a reestruturação da mesma. O número de 8 campos de estágio levava a uma curta permanência do aluno em cada local, com grande rotatividade, o que dificultava a aprendizagem. Em relação aos professores havia uma tentativa de sistematização da Integração Docente Assistencial (IDA) e de implementação de outras atividades inerentes ao ensino, pesquisa e extensão.

Èm decorrência dessa reformulação, durante os anos de 1987-88. a disciplina foi desenvolvida com apenas 4 campos de ensino clínico, alocando dois professores em cada um.

Ao avaliar este periodo, constatamos qie houve melhoria do ensino, implementação da II) $\Lambda$, maior integração dos professores nos respectivos campos de prática, bem como participação em atividades científicas e $\mathrm{cm}$ cursos de capacitação docente.

Em 1988, analisando as atribuições do enfermeiro em pediatria questionamos se estáamos realmente, capacitando nossos alunos para realizar efetivamente tais atribuições e levantamos indagações relativas a adequação do conteúdo tébrico e prático of erecido, bem como solbre os metodos de ensino e estratégias de avaliação utilizados.

Aproveitando a oportunidade do retorno de um dos docentes que, recentemente, havia realizado curso de aperfeiçamento sobre o ensino de atenção primária de saúde no exterior, os professores da disciplina decidiram pela sua capacitação pedagogica. estudando e aplicando a metodologia apreendida pela referida colega.

\section{FUNDAMENTAÇÃo TEÓRICA PARA A REESTRUTURAÇÃo DA DISCIPLINA ENFERMAGEM PEDIÁTRICA}

Face a necessidade apresentada pelos professores, foi programado um seminário sobre "Processo Ensino-Aprendizagem", no qual foram estudados 
aspectos teóricos baseados na metodologia proposta por $\Lambda \mathrm{BB} \Lambda \mathrm{TT}$; MCMAH()N (1985), o que permitiu uma análise crítica do processo ensino-aprendizagem que vinha sendo desenvolvido pela disciplina.

ABBATT; MCMAHON (1985) são docentes da area de educação e trabalham o processo ensino-aprendizagem numa abordagem sistematizada.

Essa metodologia tem sido proposta por outros educadores, tendo se iniciado durante a II Guerra Mundial (KEMP, 1985) numa tentativa de tornas as propostas educacionais mais adequadas às necessidades do estudante. e da realidade e, conseqüentemente, mais efetivas e eficazes.

O primeiro pressuposto é que se vai planejar um curso/programa para educação de adultos, profissionais ou futuros profissionais. Neste sentido. os autores sugerem que o planejamento seja baseado nas competências daquele profissional, que devem ser buscadas em todas as fontes disponíveis, ou seja. no proprio trabalho, nos currículos, nas leis existentes, no próprio profissional, nas necessidades da comunidade, dentre outras.

Após a definição da competência do profissional que se pretende formar, estas devem ser subdivididas em tarefas que, ao serem analisadas, irão mostrar o que o estudante precisa aprender para o desempenho das mesmas.

Para $\triangle B B \Lambda^{\prime} T^{\prime} T$; MCMAHON (1985) a analise das tarefas o essencial porque permite a definição de conhecimentos, atitudes e habilidades a serem ensinadas. Para eles o conhecimento e a atitude são os fatores capacitantes que fornecerão a base para o desempenho de qualquer tarefa. Porém, o de. sempenho de uma tarefa requer mais que conhecimento e atitude; e necessário uma ou mais habilidades que são chamadas de habilidades de desempenho, como se vê abaixo:

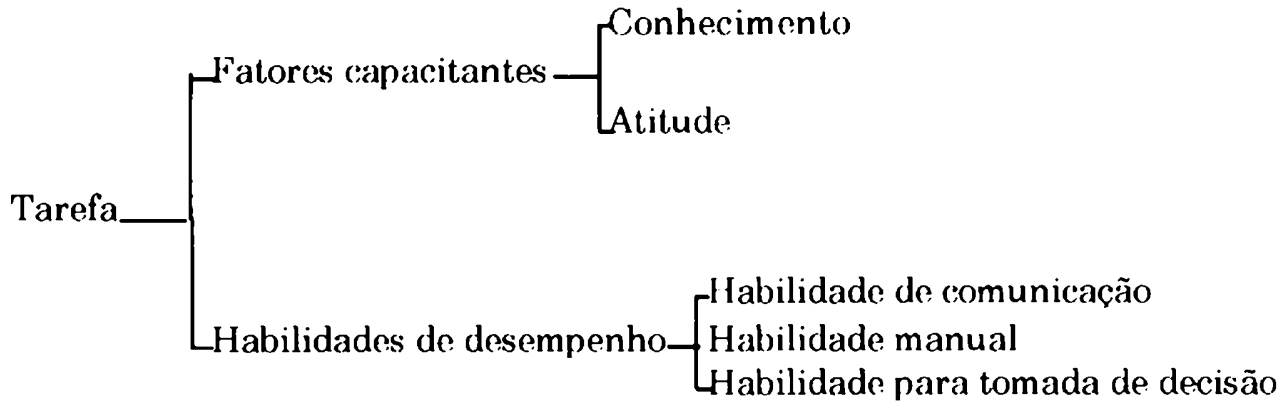

E ainda nesta etapa do planejamento que o professor deve decidir sobre qual conhecimento ensinar. E importante refletir sobre a relevância e necessidade do conhecimento, tendo sempre como referência a competência esperada do futuro profissional. 
Para os autores o "conhecimento relevante define o que todo estudante tem que saber para fazer bem o seu trabalho". É o conhecimento essencial que deve ser apreendido por todos os estudantes. Depois de apreendido, tanto estudantes quanto professores podem ampliar seu conhecimento de acordo com seus interesses.

Essa idéia tem sido expressa como o "conceito de alvo" que divide o conhecimento em três categorias: essencial, de apoio e interessante, como pode ser visto no esquema abaixo:

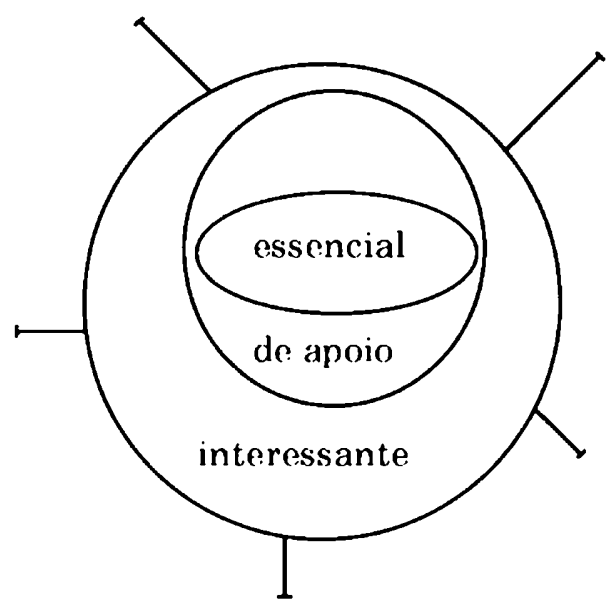

Traduzido do original: ABBATT, F.: MCMAHON, R. Teaching healt-care workers: a practical guide. London. Macmillan. 1985

Segundo os referidos autores, a partir da definição das competências e as tarefas analisadas, a próxima etapa do processo e a definição dos objetivos pedagógicos e do conteúdo a ser ensinado. Esses então, irão indicar os métodos de ensino e/ou de avaliação que deverão ser utilizados.

ABBATT: MACMAHON (1985) chamam a atenção dos professores sobre a importância de se conhecer bem todos os métodos de ensino e avaliação disponíveis para que, ao planejar um curso/aula, seja possivel escolher aquele que melhor se adeque ao objetivo pedag6gico proposto. Por exemplo, se tem como objetivo ensinar ao estudante uma habilidade manual, provavelmente uma aula expositiva não será suficiente para ensinar e uma prova escrita não permitira ao professor avaliar com segurança o aprendizado do estudante. 
Outro aspecto fundamental dessa abordagem sistematizada 6 a avaliacão do curso ou programa que os autores chamam de controle de qualidade. E necessário que, ao se implementar um curso/programa educacional, façam-se contínuas avaliações dos diferentes componentes do processo: atuação docente, qualidade e adequação dos materiais instrucionais, resultados finais dos estudantes, eficiência e eficácia de ex-alunos na prática profissional, dentre outras.

Sugerem ainda que os professores do curso/programas criem um serviço de apoio para orientação dos estudantes desde sua adaptação inicial até reflexões sobre seu desempenho durante o curso. Ist to permite feed-back professor-aluno com melhor aproveitamento do curso.

Todas as etapas propostas na metodologia descrita, desde a definição das competências ató a avaliação do curso/programa, visam melhor desempenho do estudante no processo ensino/aprendizagem para que como profissional tenha maior impacto sobre os problemas de sua área de atuação.

\section{ETAPAS DA REESTRUTURAÇÃO DA DISCIPLINA ENFERMAGEM PEDIÁTRICA}

De acordo com a metodologia propos ta por $\triangle B B^{\prime} A^{\prime} T$ ' : MCM $A H O N$ (1985), a reestruturação da disciplina obedeceu as seguintes etapas:

- Levantamento das atividades desempenhadas pelo enfermeiro de pediatria, em ambulatório e hospital (anexo I). Para isso, consideramos o que o enfermeiro graduado tem feito na prática as propostas do Sistema Único de Saúde, a Lei do Exercício Profissional do Enfermeiro, o atual currículo mínimo de enfermagem, prioridades na área de saúde da criança dentre outros.

- Sub-divisão das atividades em tarefas e posterior análise das mesmas para definição de conhecimentos, atitudes e habilidades requeridas para seu desempenho.

- Redefinição do objetivo geral e dos objetivos pedagogicos segundo os assuntos a serem ensinados, obedecendo as unidades do programa que estava sendo implementado pela disciplina enfermagem pediátrica.

- Distribuição dos assuntos em um cronograma viável. considerando a carga horária teórica e prática disponiveis.

- Redefinição dos métodos de ensino e avaliação usados pelos professores, após estudo aprofundado dos mesmos. Quanto aos métodos de avaliação, os mesmos foram adequados aos conhecimentos, atitudes $\mathrm{e}$ habilidades ensinados para cada conteúdo teórico. Isso exigiu a reformulação de provas e dos instrumentos de avaliação do aluno no campo de prática. 
- Criação de instrumentos de avaliação do programa da disciplina, atraves de avaliaçoes feitas pelos discentes (anexo II, III, IV) e docentes.

- Realização de orientação ao estudante, individualmente e em grupo. Essa atividade foi proposta para orientar e apoiar os alunos a partir de sua inserção na disciplina. Foram identificadas as dificuldades e lacunas de conhecimento apresentadas, bem como buscadas formas de superação das mesmas, para o melhor aproveitamento do aluno no transcurso da disciplina.

Neste sentido, a disciplina foi oferecida no perfodo proposto, obedecendo ao seguinte programa:

\section{1 - Ementa}

Estuda a assistência de enfermagem à criança e ao adolescente nos níveis primário, secundário e terciário. suas características bio-psico-sociais, partindo-se das atribuições do enfermeiro em pediatria. abordando a situacão de saúde dessa faixa etária, a educação participativa em saúde, os programas de atenção à saúde da criança e os principais riscos que acometem física e emocionalmente a criança institucionalizada.

\section{2 - Objetivo geral}

Prestar assistência de enfermagem a criança e ao adolescente. nos níveis primário. secundário e terciário.

\section{3 - Unidades do programa}

\section{Unidade I - Situacão de saúde da criancá e do adolescente}

- Indicadores de saúde da criança e do adolescente:

- Metas do governo na assistência a saúde da criança e do adolescente;

- Fatores responsáveis pela situação da saúde da criança e do adolescente:

- Atenção do enfermeiro na assistência a saúde da criança e do adolescente. 


\section{Unidade II - Educacão participativa em saúde}

- Comunicação com a mãe e criança;

- Educação para a saúde - uma abordagem participativa.

Unidade III - Programas de assistência integral à saúde da crianca

- Acompanhamento do crescimento e desenvolvimento:

- Nleitamento materno e orientação alimentar para o desmame:

- Contrôle e assistência das doenças diarréicas:

- Contrôle e assistência das doenças respiratórias agudas.

Unidade IV - Principais riscos que acometem a crianca institucionalizada

- I Iospitalização da criança;

- Desnutrição;

- Diarréia e desidratação;

- Doenças respiratórias;

- Doenças renais;

- Acidentes e negligência na infância.

\section{4 - Métodos de ensino:}

() conteúdo teórico será ministrado através de leituras de textos, aulas expositivas, dramatizações, grupos de discussão, vídeos, slides e demonstrações.

() conteúdo prático será ministrado nos seguintes campos:

- Creche - Avaliação do estado de saúde da criança e do adolescente atravess do contrôle do crescimento e desenvolvimento, vacinação, teste de acuidade visual e auditiva; atendimento de enfermagem; atividades de recreacão e estimulação da criança; educação para a saúde da criança e adolescente. da família e dos monitores da creche.

- Centro de saúde - Acompanhamento do processo de crescimento e desenvolvimento da criança, atraves de consulta de enfermagem. 
- Hospitais - Ievantamento das necessidades de saúde da criança e do adolescente, prescrição de enfermagem, execução de técnicas e cuidados básicos de enfermagem; atendimento à mãe acompanhante; atendimento à mãe/criança em terapia de reidratação oral; desenvolvimento de atividades de recreação.

\section{5 - Métodos de avaliação}

Participação nos seminários: • saúde da criança............ 7 pontos - saúde do adolescente... 7 pontos

Prova escrita sobre o conteúdo teórico. 10 pontos Avaliação do ensino clínico (4 campos de prática)........ 56 pontos Prova final........................................................... 20 pontos 'Total.......................................................... 100 pontos

\section{AVALIAÇÃO DO PROGRAMA DE REESTRUTURAÇÃO DA DISCIPLINA}

() presente programa de ensino foi proposto para 2 anos, durante os quais os professores deveriam avaliar seus resultados e decidir sobre sua continuidade. Sendo assim, teve seu início no $1^{\circ}$ semestre de 1989 o terminou no $2^{\circ}$ semestre de 1990 , tendo sido implementado com 4 turmas de estudantes subsequentes.

Nos 4 semestres foram feitas avaliações do programa, pelos docentes, sendo que a primeira experiencia foi descrita no trabalho "Processo ensinoaprendizagem: relato de experiência" (MADEIR 1990 ).

\section{Avaliação dos docentes}

()eorreram durante as reuniōes de diseiplina. quando cada um expunha a sua percepção solore sua prop ria atuação, sobre o desempenho dos alunos e as implicações da mudança proposta nos campos de prática.

()s professores foram unânimes em afirmar que a reformulação proposta, permitiu melhor clareza quanto as competencias do enfermeiro em pediatria possibilitando a adequação do conteúdo a ser ensinado.

A partir daí e dos conhecimentos adquiridos no Seminário. os docentes se sentiram mais capacitados para avançar em busca de métodos de ensino e? avaliação que melhor se adequassem aos objetivos pedagogicos, tanto para o 
conteúdo teórico, quanto prático. Isto permitiu a reformulação de aulas tebricas, sendo percebido melhor aproveitamento das mesmas por parte dos alunos.

Com relação ao desempenho dos alunos, os professores afirmaram que em geral, eles se mostraram mais motivados e participantes uma vez que conheciam antecipadamente os objetivos de cada sessão/atividade e os ins. trumentos de avaliação que seriam utilizados. Outro fator facilitador da melhoria do desempenho do aluno, ressaltado pelos professores, foi a realização da orientação individual ou em grupo, durante o desenvolvimento da disciplina, o que possibilitou maior aproximação professor/aluno.

Quanto as implicações das mudanças ocorridas no ensino clínico, os professores afirmaram que houve um impacto positivo, trazendo como resultado melhor adequação do ensino à necessidades específicas dos campos de prática, com maior atuação e autonomia dos docentes e estudantes.

\section{Avaliação dos discentes}

No programa da disciplina foram propostos 3 instrumentos de avaliação: ao término do conteado teorico (anexo II) em cada campo de prática (anexo III) e uma avaliação final (anexo IV), alem da avaliação verbal durante a orientação individual.

Os dados coletados nessas avaliações, foram organizados de acordo com os ítens da avaliação final, os quais passaremos a apresentar:

\section{- Conteúdo Teórico:}

Foi avaliado positivamente pela maioria dos alunos, salientando-se o alcance dos objetivos propostos em cada aula e a adequação dos temas para sua vida profissional, como se vê:

\section{"abrange o essencial na clínica pediátrica"; "o contếdo é básico, dinâmico e objetivo";}

\section{- Campos de Prática}

De modo geral, os alunos consideraram o tempo em cada campo muito curto e mencionaram a falta de contato com o adolescente. Discutiram pontos considerados negativos em cada um e apresentaram sugestões para sua melhoria.

Como as atividades praticas da disciplina foram desenvolvidas em quatro (4) campos distintos, passaremos a apresentar as avaliacooes discentes. relativas a cada um deles: 


\section{1 - Cenntro de Saúde.}

()s alunos relacionaram as atividades propostas para este campoe concordaram que os objetivos propostos foram plenamente atingidos.

Destacaram a importância da atuação do professor que,com seguran. ça. conhecimento e bom relacionamento com funcionários e alunos, conseguiu mostrar o papel do enfermeiro e suas ações em um serviço de puericultura.

Salientaram que a grande demanda de crianças e a disponibilidade de recursos materiais, tambem foram preponderantes para a aprendizagem.

Apontaram dificuldades encontradas durante o estágio. apresentaram sugestoos o apesar disso. classificaram este eampo como muito bom, uma vez que conseguiram perceber a importância do acompanhamento do crescimento e desenvolvimento da criança, atraves da consulta de enfermagem.

\section{2- Creche}

Neste campo, os alunos ressaltaram a importância da presença do enfermeiro no controle de saúde das crianças e a autonomia e integração dos professores com o campo de prática.

Fizeram modificações no sistema de arquivo dos prontuários de controle de saúde das crianças da ereche.

Destacaram também o valor das discussões sobre as patologias mais comuns nessa população infantil e afirmaram que os objetivos do ensino clínico foram alcançados.

\section{Unidade Pediátrica e Hospital Geral}

Prestar assistência a criança hospitalizada. entender e vivenciar osistema de internação conjunta o comprovar as vantagens do trabalho multiprofissional, foram os pontos mais destacados pelos alunos nesse cam. po.

Ressaltaram que a presença, segurança e participacão do professor. minimizou o stress do estudante ao cuidar de uma criança doente e facilitou a reflexão dos mesmos sobre o fazer do enfermeiro em pediatria.

Como dificuldade. a maioria aponta a superpopulação de estudantess da área da saúde em relaşão ao número de crianças hospitalizadas e a con. seqüente limitação de espaço físico para as atividades de ensino-aprendizagem.

\section{4- Ilospital Pediátrico.}

Lisse campo foi utilizado durante 2 semestres. não sendo possível sua continuidade devido as constantes greves que ocorreram no setor de saúde do Serviço Público estadual. 
Neste período, os alunos salientaram a importância de atuarem no preparo e administração de medicamentos, embora a atividade exigisse maior disponibilidade do professor com o aluno neste momento em detrimento dos demais.

Como ponto negativo mencionaram a falta de oportunidade de atuarem na Unidade de Terapia de Reidratação Oral (T.R.O.), devido a freqüentes "fechamentos provisorios" por falta de pessoal de enfermagem.

\section{- Métodos de Ensino}

()s métodos de ensino utilizados foram considerados pelos alunos como: "muito bons", "inovadores", "bem planejados".

Para tal, justificaram:

"Fuvorece visão crílica e melhor aprendizagem";

"Tnovadores, levando o aluno a ser sujeito do processo alravés de. dramatizações, simulações, dentre outros";

"Possibilita agir como enfermeiro e não só como executor de técnicas";

"As aulas não foram cansativas e o professor estava sempre preocupado com o aprendizado";

"Deu liberdade ao aluno de opinar e tentar mudar";

\section{- Estratégias de avaliação da aprendizagem}

Neste item os alunos são levados a refletir sobre os diferentes instrumentos de avaliação da aprendizagem utilizados.

Èm relação à avaliação dos seminários disseram que foi "olimo". "abrangente", porém "extensa" e "cansativa".

Quanto à prova do conteúdo tébrico, muitos a consideram "bem elaborada", "coerente" e "objetiva", enquanto ou tros disseram ter sido "muito gran. de", "cansativa" e muito "térica".

Para os alunos, a avaliação nos campos de prática foi adequada, com pontos bem distribuídos, ressaltando a importância de serem avaliados pela atuação como futuros profiss ionais e não como meros executores de técnicas.

$\Lambda$ prova final, apesar de ser muito descritiva, "testou os conhecimentos teóricos e práticos". "explorou a prática vivenciada" e "estimulou o raciocínio do aluno". 


\section{- Orientação Individual}

$\Lambda$ proposta de orientação dos alunos foi feita para que os professores pudessem acompanhar o desempenho individual do estudante durante o desenvolvimento da disciplina.

Destacaram que foi uma experiência inovadora e a consideram importante, porque valoriza o aluno, apoiando-o e orientando-o em suas dificuldades individuais, facilitando a relação professor/aluno.

\section{- Importância da disciplina para a vida profissional}

Através das respostas dos estudantes, verificamos que esta questão desencadeou a reflexão dos alunos como futuros enfermeiros, sendo que alguns disseram ter se identificado com a enfermagem pediatrica, aumentan. do a perspectiva de profissionalização futura. Ressaltaram que, após cursa. rem a disciplina, mudaram o conceito de que o enfermeiro so trabalha com criança doente o conseguiram então ter uma visão do enfermeiro como educador na prevenção da doença e manutenção da saúde da criança.

Como pode ser verificado nas avaliações a implementação do projeto de restruturação da disciplina enfermagem pediátrica permitiu aos docentes melhor clareza. quanto aos pontos positivos e negativos decorrentes dessa reestruturação. com conseqüente discussão e implementação das possíveis soluçooss para as dificuldades apontadas pelos alunos.

\section{CONCLUSÃO}

Considerando as peculiaridades da enfermagem como uma profissão da área da saúde. entendemos que o ensino da mesma deve estar sempre em sintonia com a competencia esperada do futuro profissional.

Refletindo sobre o processo vivido atraves da proposta de reestrutu ração da disciplina, constatamos a importância da metodologia utilizada, uma vez que permitiu melhor clareza das competências do enfermeiro em Pediatria e melhor desempenho do professor e do aluno no processo ensino-aprendizagem.

(os resultados das avaliaçóes dos docentes e dos discentes reafirmaram a necessidade de contínuas reflexões sobre a prática docente, na busca de novas formas de ensinar, que sejam adequadas às reais necessidades e que tenham maior impacto sobre a situação de saúde da população brasileira. 
PAULO, I.M.A. et al. Reorganization of the pediatric nursing subject from the nursing school at the Federal University of Minas Gerais: evaluation of the process. Rev.Esc.Enf.USP, v.29, n.2, p.115.32, aug. 1995.

In this paper, the faculty from the Pediatric Nursing Subject (Undergraduate Course) at the Nursing School of Universidade Federal de Minas Gerais evaluate a teaching project. Its main purpose was to reorganize the Subject based on ABATT; MCMAHON's approach to the teaching-learning process. The authours evaluate the results and highlight the positive aspects occurred due to the reorganization and confirm the need to continue the process.

UNITERMS: Nursing Education. Pediatric Nursing.

Pediatric Nursing Teaching.

\section{REFERÊNCIAS BIBLIOGRÁFICAS}

ABBATT. F.; MCMAHON, R. Teaching health-care workers: a practical guide. London.

Macmillan. 1985.

KEMP, J.E. The instructional design process. New York. Harper \& Ron, 1985.

MADEIRA. L.M. Processo ensino-aprendizagem: relato de experiéncia. Rev.Esc.Enf.USP. v.24, n. 3, p. 403.10, 1990. 


\section{ANEXO I \\ ATIVIDADES DESEMPENHADAS PELO ENFERMEIRO EM PEDIATRIA}

1 - Nível primário e secundário de atenção à criança

a) Consulta de enfermagem à criança e ao adolescente

- IListórico de enfermagem

- Exame físico

- Avaliação da situação de saúde da criança ou adolescente e família

- Prescrição de enfermagem

- Encaminhamentos para outros profissionais ou serviços.

b) Execução de técnicas gerais e especificas: administração de medicamentos. curativos, vaporização, micronebulização. administração de TRO), colheita de material para exames (fezes, urina, etc.), antropometria.

c) Prescrição de tratamentos padronizados pela instituição e/ou usados em campanhas de saúde pública: vermífugos, antianêmicos, reidratante oral, dentre outros. Saúde.

d) Wxecuçāo e/ou orientação de vacinas preconizadas pelo Ministério da

e) Educação para a saúde: individual e em grupo.

1) Administração da assistência de enfermagem em ambulatórios de pediatria:

- supervisionar execução de técnicas pelas auxiliares:

- avaliar a necessidade de atendimento das crianças para encaminhamentos:

- implantar e implementar programas de assistência à criança e/ou adolescente:

- prever e distribuir pessoal de enfermagem:

- orientar o trabalho dos auxiliares:

- planejar e implementar educação em serviço.

g) Promover participação comunitária

h) Fazer visita domiciliar. 
2) Nível terciário de atenção à criança (lospital)

a) Fazer admissão e alta da criança e adolescente.

b) Planejar a assistência de enfermagem para a criança ou adolescente admitido na unidade pediátrica.

c) Prestar assistência de enfermagem à criança e ao adolescente hospitalizado

d) Orientar o supervisionar os cuidados prestados por auxiliares e atendentes de enfermagem a criança e ao adolescente, quanto a: higiene. alimentação, hidratação oral, sondagens, administração de medicamentos, coleta de material para exames, curativos, preparo para cirurgia, oxigenioterapia, dentre outros.

e) Avaliar a assistência prestada à criança e ao adolescente.

f) Prever e distribuir pessoal de enfermagem.

g) Planejar, executar e avaliar treinamento em serviço.

h) Coordenar o trabalho da equipe de enfermagem.

i) Promover o trabalho multi-profissional. 


\section{ANEXO II}

\section{AVALIAÇÃo DE CONTEÚDO TEÓRICO}

Terminamos o conteúdo teórico da disciplina Enfermagem Pediatrica. Sentimos ser imprescindível sua colaboração concreta c crítica no que tange a avaliação desse conteúdo, uma vez que ter sido você o sujeito vivenciador do processo ensino-aprendizagem.

\begin{tabular}{|c|c|c|c|}
\hline ASSUNTO & $\begin{array}{l}\text { O QUE FOI } \\
\text { BOM }\end{array}$ & $\begin{array}{c}\text { PODE SER } \\
\text { MELHORADO }\end{array}$ & $\begin{array}{l}\text { FICOU } \\
\text { OMISSO }\end{array}$ \\
\hline $\begin{array}{l}\text { Situaçăo de saúde da criança } \\
\text { Comunicaçao com a mãe e a crian } \\
\text { Educaçao participativa } \\
\text { Anamnese e exame físico } \\
\text { Alimentaçáo } \\
\text { Desnutriçáo } \\
\text { Acidentes na infáncia e a criança } \\
\text { negligenciada } \\
\text { Admissão e alta } \\
\text { Terapêutica nas verminoses, } \\
\quad \text { dermatoses e anemias } \\
\text { D. Diarréicas } \\
\text { Renal } \\
\text { Respiratório } \\
\text { Cálculo de dosagem, dituiça de } \\
\text { medicamentos e soro } \\
\text { Terapia de Reidrataçao oral } \\
\text { Consulta de enfermagem } \\
\text { Seminário I } \\
\text { Seminário II }\end{array}$ & & & \\
\hline
\end{tabular}




\section{ANEXO III}

\section{AVALIAÇÃo PARCIAL DA PARTE PRÁtiCA}

\section{1 - Orientações}

Esta avaliação será feita em grupo. Cada grupo escolherá um "repor. ter" que terá as seguintes atribuições:

- Entrevistar os colegas

- Relatar os resultados das entrevistas na sala de aula, para todo o grupo

- Devolver o resultado das entrevistas para o coordenador da disciplina.

\section{2 - Roteiro para Entrevista}

CAMP() DE EST'TÁ(XIO - Denomine-o

- Que atividades foram propostas neste campo de estágio?

- () que você considera ter realmente aprendido neste campo?

- O que você gostaria de ter aprendido neste campo?

- Por que não aprendeu?

- De modo geral, você sentiu que o professor contribuiu pouco, dentro da media ou muito para sua aprendizagem? Por que?

- Em relação ao campo, liste:

() que facilitou sua aprendizagem.

() que dificultou sua aprendizagem. 


\section{ANEXO IV}

\section{AVALIAÇÃO FINAL}

Com o propósito de avaliar a disciplina Enfermagem Pediatrica após ter sido reestruturada, pedimos a você, aluno que viveu todo o processo de modificação da mesma, portanto sujeito da experiência, que faça a avaliação final de forma consciente.

1) Qual a sua opinião sobre o conteúdo teórico da disciplina?

2) Qual a sua opinião em relação ao ensino clínico desenvolvido nos campos de prática: Centro de Saúde, Greche, Unidade Pediátrica do Hospital e Centro (ieral de Pediatria?

3) Comente sobre as metodologias de ensino utilizadas durante a disciplina.

4) Comente sobre as avaliações: seminários, prova tébrica, campos de prática e prova final.

5) De que maneira a orientação individual com os professores influenciou sua aprendizagem?

6) Qual a importância da Enfermagem Pediátrica para a sua vida profissional? 